\title{
INTRAOSSEOUS TRANSCUTANEOUS AMPUTATION PROSTHESES VERSUS DENTAL IMPLANTS: A COMPARISON BETWEEN KERATINOCYTE AND GINGIVAL EPITHELIAL CELL ADHESION IN VITRO
}

\author{
C.J. Pendegrass*, H.T. Lancashire, C. Fontaine, G. Chan, P. Hosseini and G.W. Blunn \\ University College London, The Institute or Orthopaedics \& Musculoskeletal Science, \\ Centre for Biomedical Engineering, The RNOH, Brockley Hill, Stanmore, Middlesex, HA7 4LP, UK
}

\begin{abstract}
Infection is the primary failure modality for transcutaneous implants because the skin breach provides a route for pathogens to enter the body. Intraosseous transcutaneous amputation prostheses (ITAP) are being developed to overcome this problem by creating a seal at the skinimplant interface. Oral gingival epithelial cell attachment creates an infection-free seal around dental implants. However, this has yet to be achieved consistently outside of the oral environment. Epithelial cells attach to metal substrates by means of hemidesmosomes and focal adhesions. Their density per unit cell is an indicator of attachment strength. We postulate that gingival epithelial cells express more hemidesmosomes and focal adhesions at earlier time points, compared with epidermal keratinocytes, and this increased speed and strength of attachment may be the reason why an infection-free seal is often achieved around dental implants but less frequently around ITAP. The aim of this study was to compare epidermal keratinocyte with oral gingival cell attachment on titanium alloy in vitro, to determine whether these two cell types differ in their speed and strength of attachment. We aimed to test the hypothesis that gingival cells up-regulate focal adhesion and hemidesmosome formation at earlier time points compared with extra-oral keratinocytes. To test this hypothesis we cultured epidermal keratinocytes and oral gingival cells on titanium alloy substrates and assessed cell attachment by focal adhesions and hemidesmosome expression at 4, 24, 48 and 72 hours. Formation and expression of hemidesmosomes temporally lagged behind that of focal adhesions in both cell types. Gingival derived cells up-regulated focal adhesion and hemidesmosome expression at earlier time points compared with epidermal keratinocytes. Hemidesmosome expression in oral gingival cells was 3 times greater compared with epidermal keratinocytes at 4 hours. Our findings indicate that earlier attachment may be key to the success of the dental implant transcutaneous interface.
\end{abstract}

Keywords: Gingival cell, epithelial cell, cell attachment, focal adhesion, hemidesmosome, laminin.

*Address for correspondence:

Catherine Pendegrass

Centre for Biomedical Engineering

Institute of Orthopaedics and Musculoskeletal Science University College London, Stanmore, UK

Telephone number: +44 2089540268

E-mail: c.pendegrass@ucl.ac.uk

\section{Introduction}

Dental implants, pioneered by Brånemark, have been used successfully to treat edentulous patients since the 1960s (Adell et al., 1970; Marks et al., 2001; Odman et al., 1988). They have been shown to be safe and reliable, with survival rates of over $90 \%$ at 15 years (Adell et al., 1986; Brånemark et al., 1982; Tillander et al., 2010). Their success relies on osteointegration and the attachment of the gingiva to the implant, which occurs through a junctional epithelium (JE) (Raisanen et al., 2000). The epithelial cells form a tight collar around the implant, as they do around teeth, with hemidesmosomes connecting the bordering epithelial cells of the JE, by a basal lamina-like extracellular matrix termed the internal basal lamina (IBL), to the titanium (Fig. 1). This prevents downgrowth, often termed marsupialisation or pocket formation. In downgrowth, the epidermal tissues grow down around the implant, separating it from the surrounding tissues, causing mechanical instability (Hansson et al., 1983). The pocket that is formed allows bacterial colonisation leading to an increased risk of infection. Translation of dental implant technology into a solution for attaching artificial limbs for amputees, could overcome the problems associated with traditional stump-socket devices, which include tissue necrosis, poor socket fitting, pain and functional impairment (Dudek et al., 2005; Lyon et al., 2000). However, despite common design concepts, skin-penetrating transcutaneous implants used for attachment of artificial limbs have been reported to have much higher infection rates compared with dental implants; with infectious complications

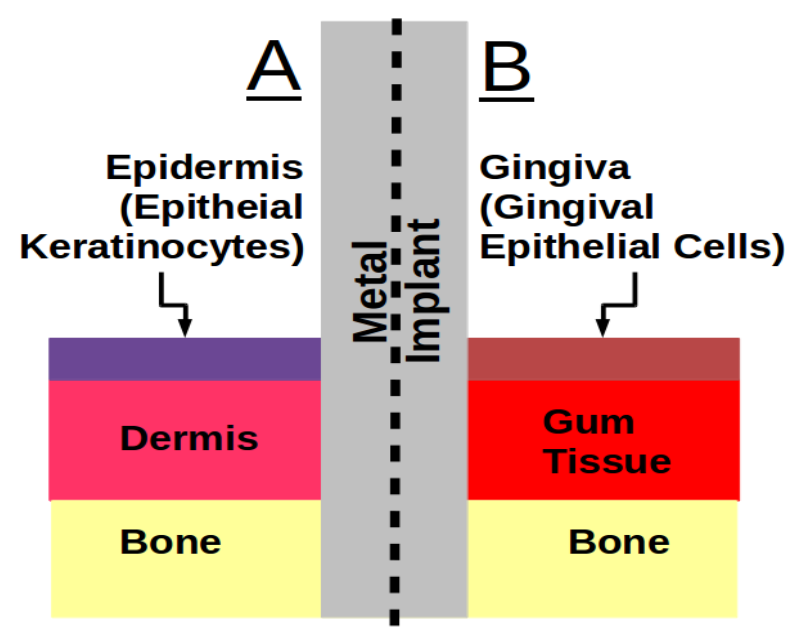

Fig. 1. Schematic demonstrating the soft tissue interface around ITAP (A) and a dental implant (B). 
being reported in $40 \%$ of patients during the first 3 years post-operation (Tillander et al., 2010). Infection occurs because of downgrowth caused by failure of the epithelial cells to form a seal at the skin-implant interface, which prevents bacterial infection (Pendegrass et al., 2006a). Intraosseous transcutaneous amputation prostheses (ITAP) are being developed to overcome these problems by promoting soft tissue attachment at the epithelial-implant interface, which is capable of preventing infection long-term (Middleton et al., 2007; Pendegrass et al., 2006b; Pendegrass et al., 2008; Pendegrass et al., 2010). A schematic, showing the ITAP concept, is shown in Fig. 1.

In order to prevent downgrowth, attachment of the cells in the epidermis to the implant surface is critical in order to prevent their migration, and subsequent infection. The success of dental implants may be due to earlier attachment of gingival epithelial cells, by hemidesmosomes and their pre-cursors; focal contacts, to the implant surface compared with extra-oral keratinocytes around skin-penetrating amputation prosthetics. If this is true, implant material-engineering and augmentation strategies to encourage earlier attachment of keratinocytes may reduce downgrowth and infection rates in ITAP. Hemidesmosomes facilitate stable adhesion of epithelial cells to the underlying basement membrane. Hemidesmosome stability relies on multiple interactions with a number of protein components that form a complex that is tightly embedded in the membrane (Walko et al., 2014). The core of this complex is the $\alpha 6 \beta 4$ integrin, which binds to the extracellular matrix protein laminin-332 (laminin $\alpha 3, \beta 3, \gamma 2$ - previously termed laminin 5 (Aumailley et al., 2005)). To further our understand the reasons for the poorer skin barrier created around transcutaneous devices compared with gingival mucosa around dental implants, we aim to test the hypothesis that gingival cells up-regulate focal adhesion and hemidesmosome formation at earlier time points compared with extra-oral keratinocytes, and that this may be facilitated by differences in laminin-332 expression.

\section{Materials and Methods}

\section{Substrate preparation}

$10 \mathrm{~mm}$ diameter titanium alloy $\left(\mathrm{Ti}_{6} \mathrm{~V}_{4} \mathrm{Al}\right)$ discs were manufactured from surgical grade titanium alloy (BS7252PT3). The discs were polished using successive mechanical polishing with P1200 to P4000 grade polishing paper and Buehler Micropolish $1.0 \mu \mathrm{m}$ alumina (Buehler, Coventry UK) on and Exact-Micro-Grinding system (Mederex, Bath, UK). The surface finish on the discs measured $0.03 \mu \mathrm{m}$ Ra. Discs were sterilised by autoclaving in a 2100 Classic Clinical Autoclave (Prestige Medical, Lancs, England) for $11 \mathrm{~min}$ at $126{ }^{\circ} \mathrm{C}$ and $140 \mathrm{kPa}$ pressure.

\section{Study design}

The study was performed in three parts. The cells used in experiment one were human, un-matched cells (i.e. not from the same donor). The speed and strength of attachment of un-matched human oral keratinocytes were compared with that of extra oral keratinocytes. In experiment two, in order to determine whether the results for the un-matched human cells would be consistent with those from matched donors, primary ovine gingival and extra-oral keratinocytes were harvested, culture expanded and subjected to identical assays. In experiment three, a qualitative assessment of laminin-332 expression was performed on human un-matched cells (used in experiment one) to determine the abundance and distribution of the ECM peptide and its influence on the speed and strength of cell attachment. All assays were performed in triplicate and on the substrate materials prepared as described below.

\section{Cell culture and seeding}

Attachment of human oral gingival cells and epidermal keratinocytes

Primary human oral gingival epithelial cells (HGEP) (CellNTec, Buckingham, UK) were culture expanded in CnT24 Progenitor Cell Targeted (PCT) oral epithelium medium and supplements A, B and C (CellNTec, Buckingham, UK) with $1 \%$ penicillin /streptomycin (Invitrogen, Corporation, Paisley, UK) at $37^{\circ} \mathrm{C}$ with $5 \%$ humidified $\mathrm{CO}_{2}$. Primary human epidermal keratinocytes (HPEK) (CellNTec, Buckingham, UK) were culture expanded in CNT57 PCT epidermal keratinocyte medium, with identical supplements as the HGEP. 30,000 cells, at passage $1-3$, were seeded on to the titanium alloy discs and cultured at $37^{\circ} \mathrm{C}$ with $5 \%$ humidified $\mathrm{CO}_{2}$ for $4,24,48$ and $72 \mathrm{~h}$ prior to assessment of cell attachment.

\section{Attachment of ovine oral gingival cells and epidermal keratinocytes}

Primary cells oral and extra oral keratinocytes were isolated from five sheep, immediately following euthanasia. Under aseptic conditions, two $10 \times 20 \mathrm{~mm}$ biopsies were taken from both the upper gum (above the teeth) and the skin between the abdomen and thigh. Primary ovine oral gingival epithelial cells (OGEP) and primary ovine epidermal keratinocytes (OPEK) were isolated from five sheep, immediately following euthanasia. Under aseptic conditions, two $10 \times 20 \mathrm{~mm}$ biopsies were taken from both the upper gum (above the teeth) and the skin between the abdomen and thigh. The gingival (OGEP) and extra-oral samples (OKEP) were placed in $5 \mathrm{~mL}$ CNT 32 PCT media and CNT 02 Non-PCT media (CellNTec, Buckingham, UK), respectively. Both media were supplemented with $1 \%$ penicillin /streptomycin (Invitrogen, UK) and $250 \mathrm{ng} / \mathrm{mL}$ Amphotericin B (Invitrogen, UK) at $4{ }^{\circ} \mathrm{C}$. Biopsies were floated in $5 \mathrm{~mL}$ of $0.25 \%$ Trypsin/EDTA (Invitrogen, UK) under aseptic conditions for $12 \mathrm{~h}$ at $4{ }^{\circ} \mathrm{C}$. The epidermis was gently scraped from the dermis with a sterile scalpel blade prior to magnetic stirring in $0.05 \%$ Trypsin/EDTA for $20 \mathrm{~min}$ and incubation at $37^{\circ} \mathrm{C}, 5 \%$ humidified $\mathrm{CO}_{2}$ for a further $10 \mathrm{~min}$. $10 \mathrm{~mL}$ of Dulbecco's Modified Eagle's Medium (DMEM) (D6429 Sigma-Aldrich, UK) 
supplemented with $10 \%$ FCS (First Link Ltd., UK) and $1 \%$ penicillin/streptomycin, was added to neutralise the Trypsin/EDTA, prior to filtering the solution through a $70 \mu \mathrm{m}$ mesh filter (BD Biosciences, UK). The filtrate was centrifuged for $5 \mathrm{~min}$, the supernatant discarded and the pellet re-suspended in $10 \mathrm{~mL}$ of appropriate media for each cell type. The cells were then culture-expanded before seeding as in experiment one for 4, 24, 48 and $72 \mathrm{~h}$ prior to the assessment of cell attachment.

\section{Cell attachment assays}

Following seeding, cells for both experiment one and two were incubated for $4,24,48$ or $72 \mathrm{~h}$ prior to immunolabelling of either vinculin, for quantification of focal contacts, or BP180 for hemidesmosomes according to the following methodologies.

\section{Focal contact quantification and analysis}

Focal contacts were visualised and quantified with immunolocalisation of vinculin. Cells were fixed for 5 min in $10 \%$ formal saline, permeabilised with $0.05 \%$ Triton X-100 (T8787 Sigma Aldrich, Dorset; UK) and incubated with mouse monoclonal Anti-vinculin (1:100) (V9131 Sigma-Aldrich) in PBS for $2 \mathrm{~h}$. FITC conjugated anti-mouse monoclonal secondary antibodies (F2883 Sigma- Aldrich) were applied in PBS (1:200) for $1 \mathrm{~h}$. Cell areas were measured using a Zeiss microscope linked to image analysis software (Axioimage version 4.4, Zeiss, Germany). Vinculin markers were counted from 15 randomly selected cells on each disc (vinculin count). Three discs were used in each experimental group. The density of vinculin markers (the number of vinculin markers, divided by the cell area) was calculated and used as a method of assessing cell attachment strength. The density of vinculin markers has previously been demonstrated to directly correlate with the direct biophysical strength of cell attachment (Pendegrass et al., 2010).

\section{Hemidesmosome quantification and analysis}

Hemidesmosomes were visualised and quantified with immunolocalisation of BP180. The cells were incubated with a $50 \mu \mathrm{L}$ droplet of $10 \%$ goat serum for $30 \mathrm{~min}$ to prevent non-specific antigen binding prior to incubation with rabbit monoclonal Anti-collagen XVII (BP180) (1:100) (ab28440 Abcam Plc., Cambridge, UK) in PBS for $1 \mathrm{~h}$. The primary antibody was localised with Alexa Fluor 448 anti-rabbit polyclonal antibody in PBS (1:200) (ab97047 Abcam Plc., UK) for $1 \mathrm{~h} .15$ randomly selected cells per disc were imaged using a Zeiss microscope linked to image analysis software (Axioimage version 4.4, Zeiss, Germany) and cell fluorescence was scored using a graded scale from 0 to 5 ; with 0 being no fluorescence and 5 high (Fig. 2). The scale was produced in Apple Aperture (Apple Inc., USA), with each grade having a 30 unit increase in luminance as measured using the red, green, blue (RGB) (0-256) colour values.

\section{Scanning electron microscopy}

Cell morphology was assessed using a JEOL JSM$5500 \mathrm{LV}$ scanning electron microscope (SEM) $(10 \mathrm{kV})$, at 4, 24, 48 and $72 \mathrm{~h}(n=3)$. Samples were fixed in $1.5 \%$ glutaraldehyde in $0.1 \mathrm{M}$ sodium cacodylate buffer ( $\mathrm{pH} 7.2$ ) for $24 \mathrm{~h}$. Following $10 \mathrm{~min}$ in $0.1 \mathrm{M}$ sodium cacodylate buffer, cells were stained with $1 \%$ osmium tetroxide and $1 \%$ tannic acid in $0.1 \mathrm{M}$ sodium cacodylate. Serial dehydration in industrial methylated spirit was performed prior to transferring into ethanol and then into hexamethydisalazane (HMDS). Samples were left to dry overnight, then mounted on aluminium stubs and goldpalladium sputter-coated in an Emitech K550 (Emitech Ltd. Kent, UK).

\section{Laminin-332 expression assay}

Following seeding, cells for experiment one were incubated for $4,24,48$ or $72 \mathrm{~h}$ prior to immunolabelling of laminin-332 according to the following methodology. Cells were fixed for $20 \mathrm{~min}$ in $10 \%$ formal saline and incubated with a $50 \mu \mathrm{L}$ droplet of $10 \%$ goat serum for $30 \mathrm{~min}$ to prevent non-specific antigen binding. Cells were incubated for $1 \mathrm{~h}$ with mouse monoclonal anti-human laminin alpha 3 (laminin-5) $(10 \mu \mathrm{g} / \mathrm{mL})$ (MAB2144, R\&D Systems, Abingdon, UK). The primary antibody was localised with Alexa Fluor 448 anti-mouse polyclonal antibody in PBS (1:200) (A-11059, Life Technologies Ltd., Paisley, UK). Cells were counter-stained with Hoechst 33258 in PBS (B2883 Sigma-Aldrich) for $10 \mathrm{~min}$. Cells were imaged using a Zeiss microscope linked to image analysis

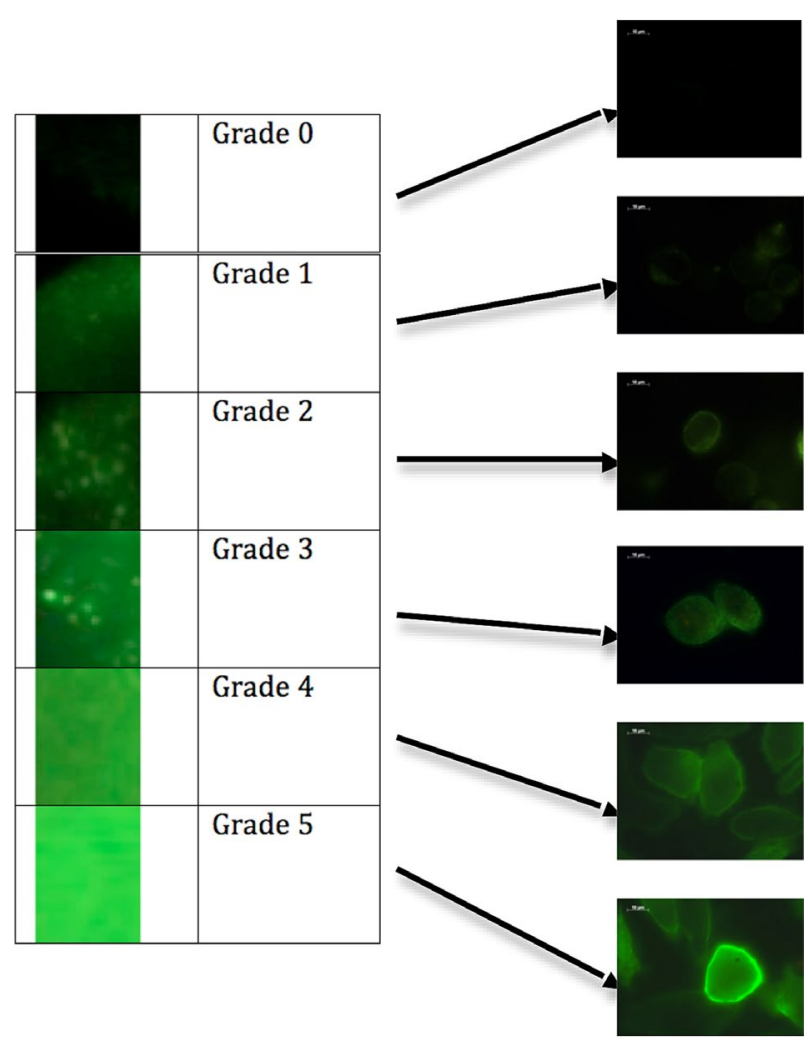

Fig. 2. Grading scale from $0-5$ used to quantify the immunofluorescence for BP180 staining. 


\section{Hours}

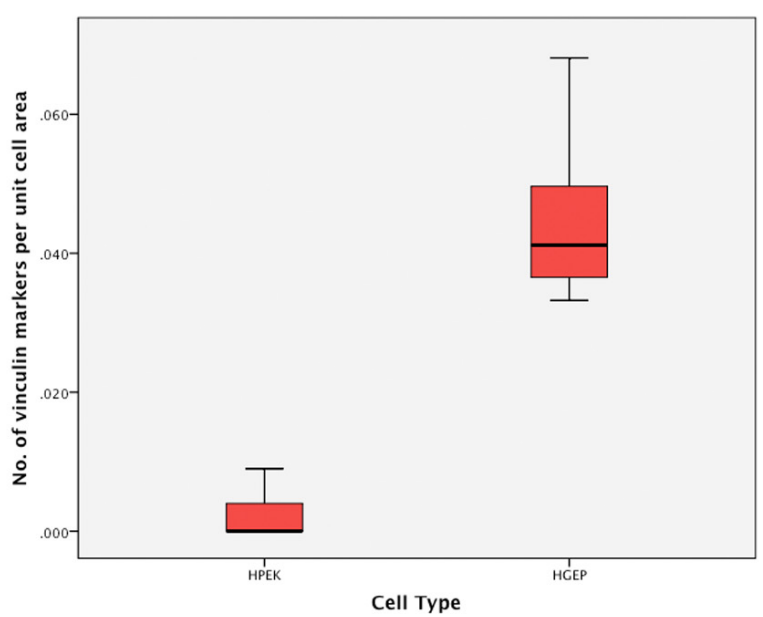

48 Hours

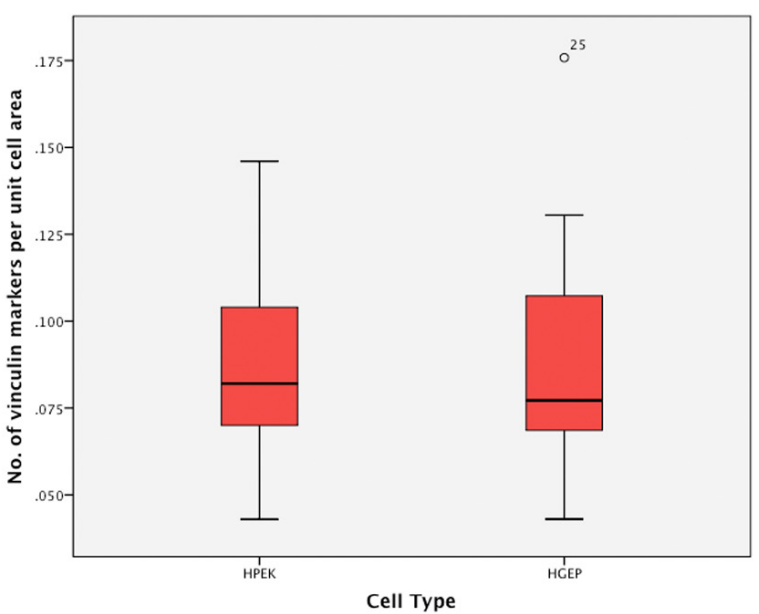

\section{Hours}

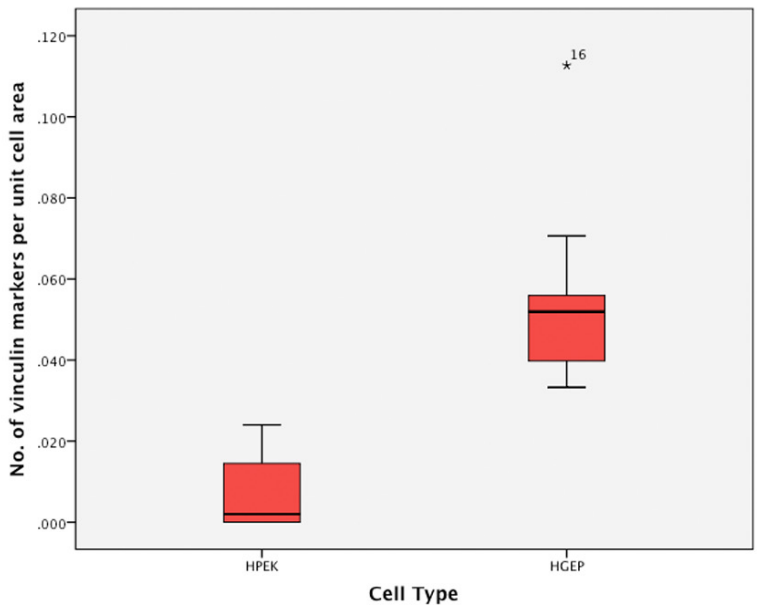

72 Hours

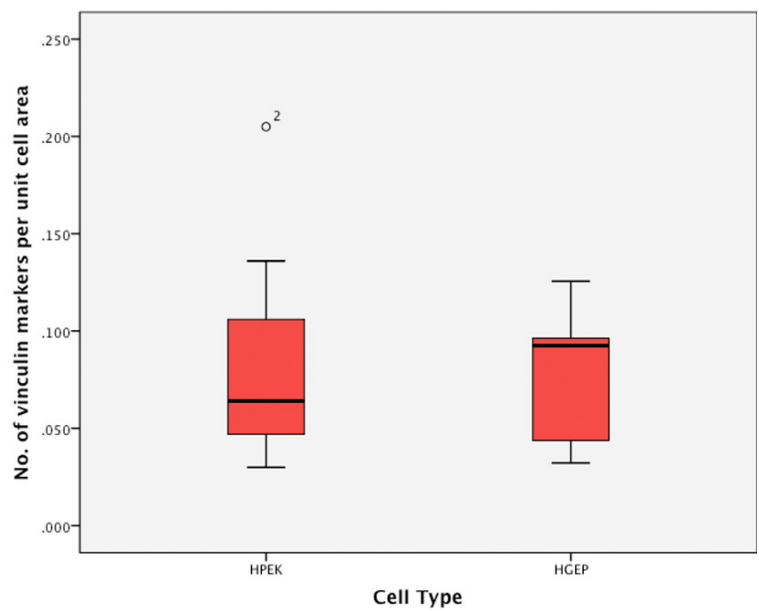

Fig. 3. Box and whiskers plots showing the number of vinculin markers per unit cell area for HPEK and HGEP at 4, 24, 48 and $72 \mathrm{~h}$.

software (Axioimage version 4.4, Zeiss, Germany) and a qualitative assessment of expression was performed.

\section{Statistical analyses}

Data were analysed using SPSS (version 19.0 for windows, Chicago, USA). The Kruskal Wallis H test (KW) was used to determine whether multiple groups were from the same population distribution. If the $p$ value obtained was $>0.05$ the data were not subject to further analyses. Data with KW $p<0.05$ were subject to pair-wise Mann-Whitney U (MWU) tests to assess differences between individual groups. Results were considered significant where the $p$ value was less than 0.05. Data are presented as median values (with $95 \%$ confidence intervals (CI)).

\section{Results}

\section{Cell attachment assays: attachment of human oral gingival cells and epidermal keratinocytes}

\section{Focal contact quantification and analysis}

The data are presented in Fig. 3 and Fig. 4. Significant differences in the number of vinculin markers per unit cell area were observed between HGEP and HPEK at $4 \mathrm{~h}$ $(p<0.001)$ and $24 \mathrm{~h}(p<0.001)$. The number of vinculin markers per unit cell area was 15 and 7.7 times greater for the HGEP compared with the HPEK at 4 and $24 \mathrm{~h}$, respectively. At 48 and 72 h, no significant differences were observed between the two cell types.

The number of vinculin markers per unit cell area in HPEK significantly increased between 4 and $24 \mathrm{~h}$ $(p=0.037), 24$ and $48 \mathrm{~h}(p=0.037)$, whilst HGEP only show a significant increase between 24 and $48 \mathrm{~h}$ $(p<0.001)$. 

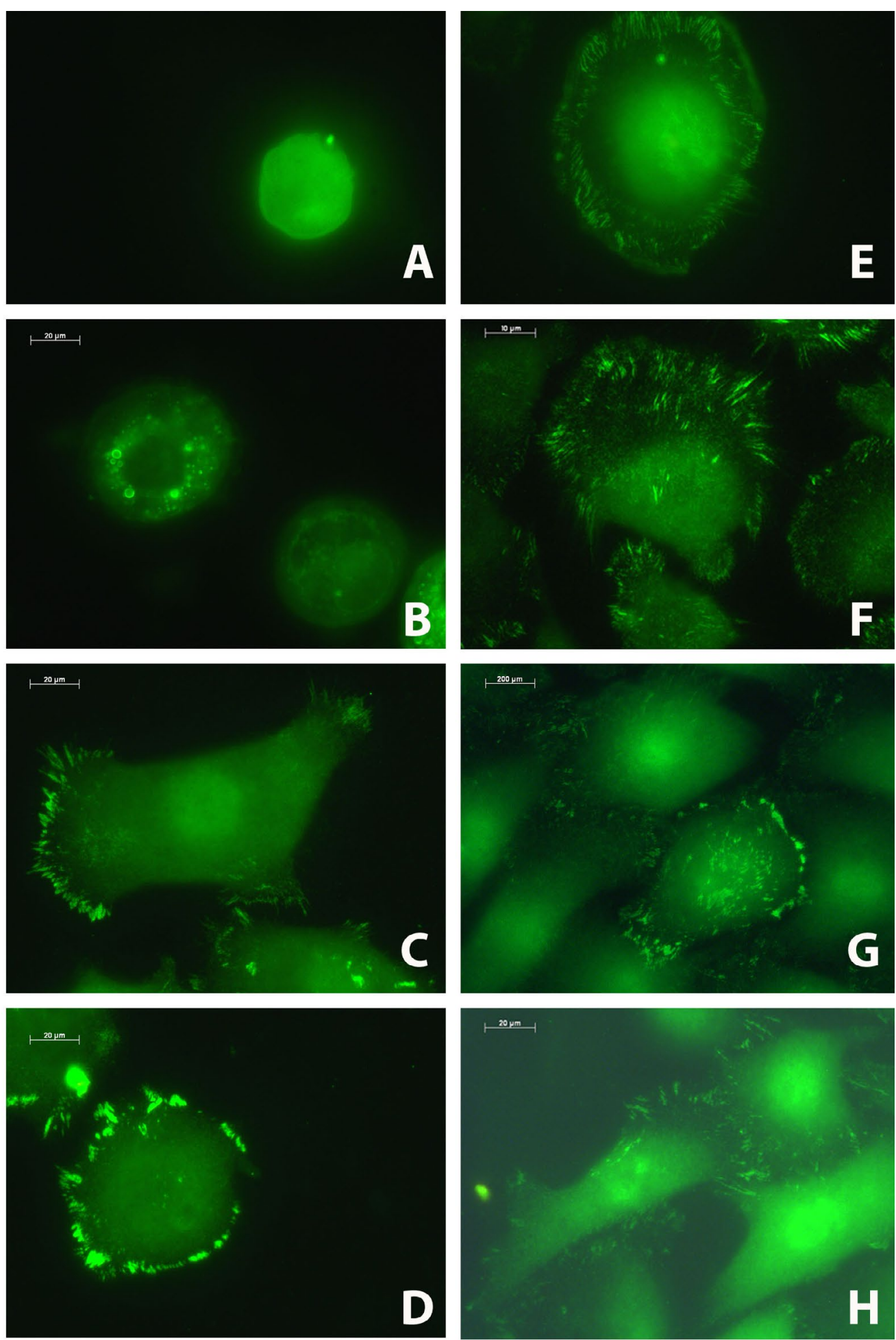

Fig. 4. Experiment one: Fluorescent microscopy images of vinculin immunolocalisation for HPEK at $4 \mathrm{~h}(\mathbf{A}), 24 \mathrm{~h}$ (B), $48 \mathrm{~h} \mathrm{(C)} \mathrm{and} 72 \mathrm{~h} \mathrm{(D)} \mathrm{and} \mathrm{HGEP} \mathrm{at} 4 \mathrm{~h} \mathrm{(E),} 24 \mathrm{~h} \mathrm{(F),} 48 \mathrm{~h} \mathrm{(G)}$ and $72 \mathrm{~h}(\mathbf{H})$.

Hemidesmosome quantification and analysis

It was difficult to visualise individual hemidesmosomes using light microscopy due to their small size and for this reason a score that semi-quantified the number of hemidesmosomes based on their overall fluorescence when conjugated with Anti BP180 was used. The BP180 score was significantly greater in HGEP compared with HPEK at $4 \mathrm{~h}(p=0.002)$. No significant differences were observed at $24(p=0.605), 48(p=0.436)$ or $72 \mathrm{~h}(p=0.258)$ (Table 1 and Fig. 5). Distinct differences were noted in cell morphology between the cell types from $24 \mathrm{~h}$, with HGEP adopting a more flattened, spread morphology compared with HPEK which were observed to be rounder with fewer cell processes (Fig. 5).

Over time, data analysis for each cell type showed that BP180 score significantly increased between all time-points in HPEK ( $p$ values $=0.040$ (between 4 and $24 \mathrm{~h}$ ), 0.019 (24 and $48 \mathrm{~h}$ ) and 0.000 (48 and $72 \mathrm{~h}$ ); however, similar increases were only observed in HGEP between 24 and $48 \mathrm{~h}(p=0.011)$, and 48 and $72 \mathrm{~h}$ 

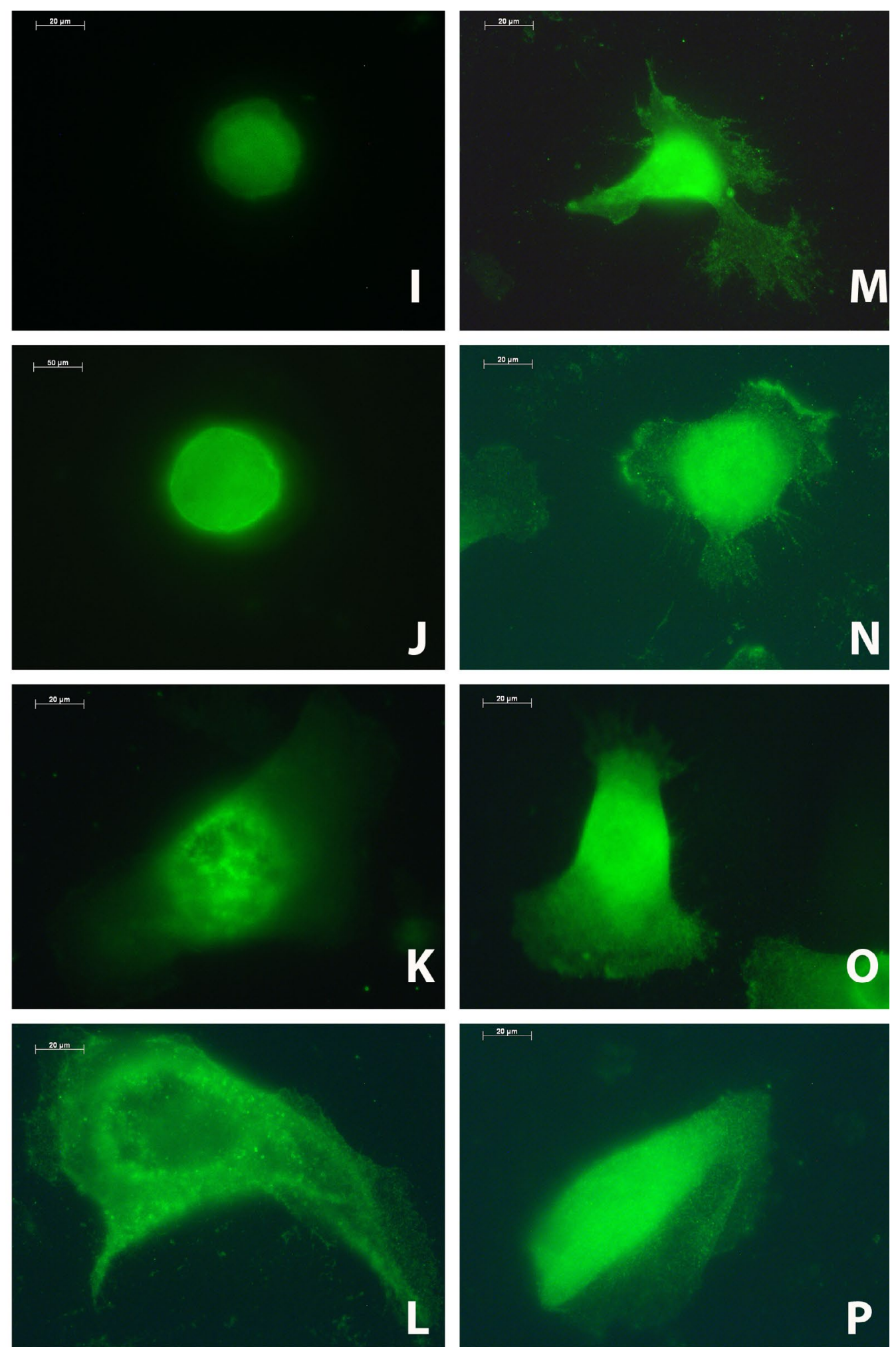

Fig. 5. Experiment one: Fluorescent microscopy images of BP180 staining for HPEK at $4 \mathrm{~h}(\mathbf{I}), 24 \mathrm{~h}(\mathbf{J}), 48 \mathrm{~h}$ $(\mathbf{K})$ and $72 \mathrm{~h} \mathrm{(L)}$ and HGEP at $4 \mathrm{~h}(\mathbf{M}), 24 \mathrm{~h}(\mathbf{N}), 48 \mathrm{~h}(\mathbf{O})$ and $72 \mathrm{~h}(\mathbf{P})$.

Table 1. Median and $95 \%$ Confidence intervals for Experiment One BP180 scores over time for HPEK and HGEP.

\begin{tabular}{|l|c|c|c|c|}
\hline \multicolumn{5}{|c|}{ Time (h) } \\
\hline Cell Type & $\mathbf{4}$ & $\mathbf{2 4}$ & $\mathbf{4 8}$ & $\mathbf{7 2}$ \\
\hline HPEK & $2.0(1.2$ to 2.0$)$ & $2.0(1.8$ to 2.9$)$ & $3.0(2.9$ to 3.6$)$ & $5.0(4.2$ to 5.0$)$ \\
\hline HGEP & $3.0(2.3$ to 3.3$)$ & $3.0(2.2$ to 3.0$)$ & $3.0(3.0$ to 3.9$)$ & $4.0(3.9$ to 5.0$)$ \\
\hline
\end{tabular}



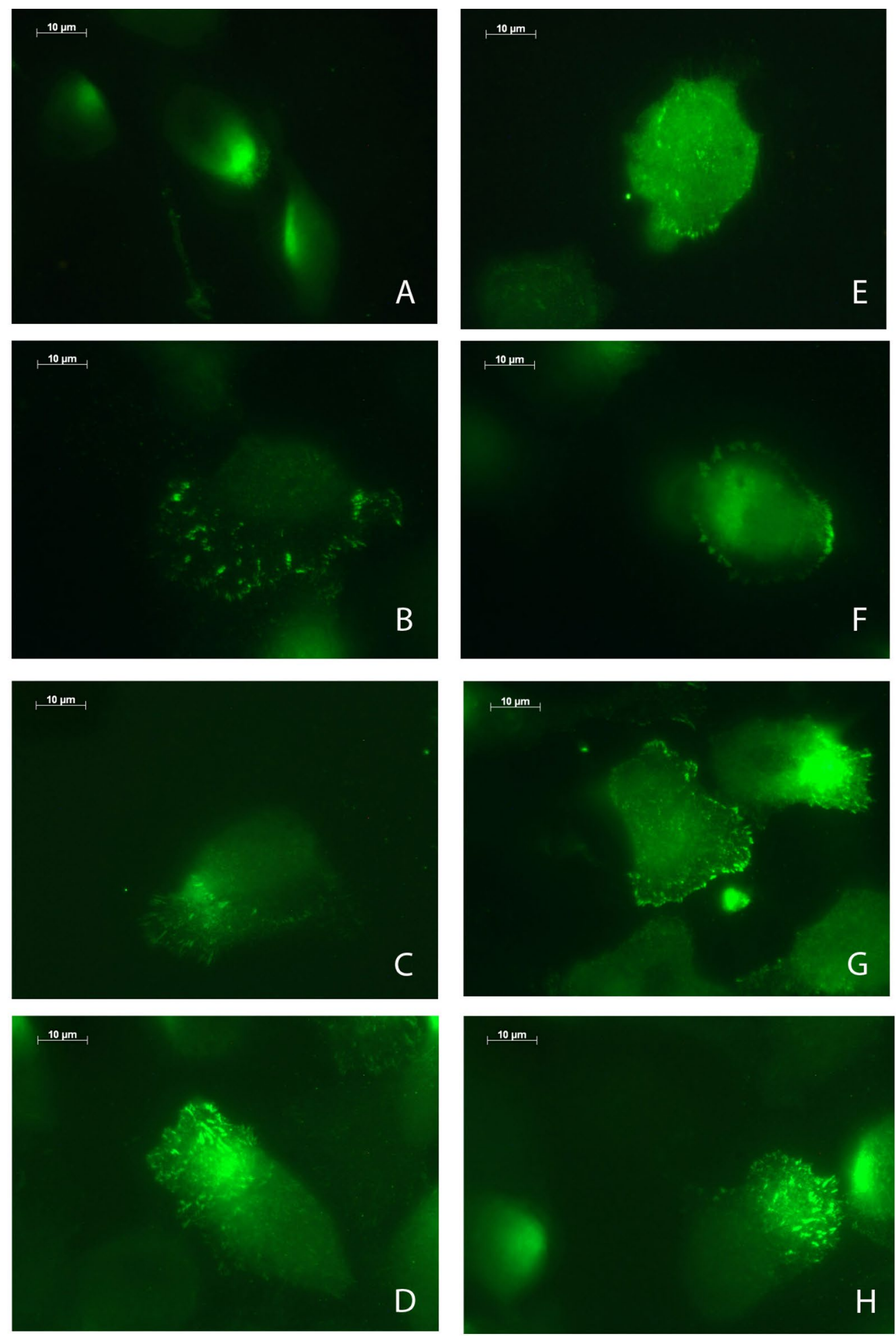

Fig. 6. Experiment two: Fluorescent microscopy images of vinculin immunolocalisation for OPEK at $4 \mathrm{~h}(\mathbf{A}), 24 \mathrm{~h}$ (B), $48 \mathrm{~h}(\mathbf{C})$ and $72 \mathrm{~h} \mathrm{(D)} \mathrm{and} \mathrm{OGEP} \mathrm{at} 4 \mathrm{~h} \mathrm{(E),} 24 \mathrm{~h} \mathrm{(F),} 48 \mathrm{~h} \mathrm{(G)} \mathrm{and} 72 \mathrm{~h} \mathrm{(H).}$

$(p=0.019)$. No significant increase was observed in HGEP between 4 and $24 \mathrm{~h}(p=0.546)$.

\section{Cell attachment assays: attachment of ovine oral gingival cells and epidermal keratinocytes}

Focal contact quantification and analysis

Significant differences in the number of vinculin markers per unit cell area were observed between OGEP and OPEK at $4 \mathrm{~h}(p=0.012), 24 \mathrm{~h}(p<0.001), 48 \mathrm{~h}$ $(p<0.001)$ and $72 \mathrm{~h}(p=0.018)$ (Table 2 and Fig. 6). The density of vinculin markers was $1.3,1.4,1.4$ and 1.2 times greater for the OGEP compared with the OPEK at $4,24,48$ and $72 \mathrm{~h}$ respectively.

The density of vinculin markers in OPEK significantly increase between 4 and $24 \mathrm{~h}(p=0.001)$, 24 and $48 \mathrm{~h}(p<0.001)$, and 48 and $72 \mathrm{~h}(p<0.001)$. Significant increases were observed for OGEP between 

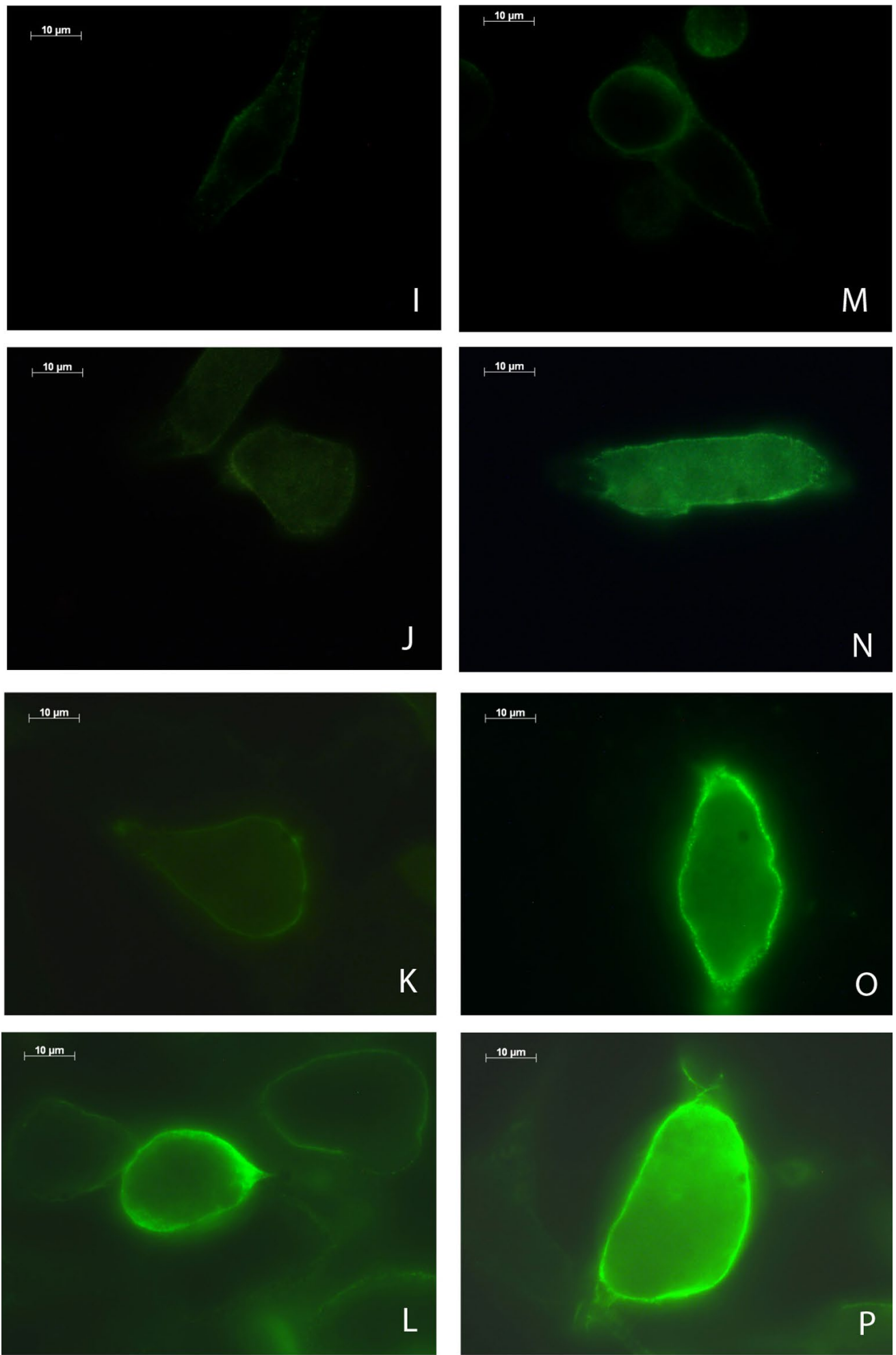

Fig. 7. Experiment two: Fluorescent microscopy images of BP180 staining for OPEK at $4 \mathrm{~h}(\mathbf{I}), 24 \mathrm{~h}(\mathbf{J}), 48 \mathrm{~h}$ (K) and $72 \mathrm{~h}(\mathbf{L})$ and OGEP at $4 \mathrm{~h}(\mathbf{M}), 24 \mathrm{~h}(\mathbf{N}), 48 \mathrm{~h}(\mathbf{O})$ and $72 \mathrm{~h} \mathrm{(P).}$

Table 2. Median and $95 \%$ Confidence intervals for Experiment Two number of vinculin markers per unit cell area over time for OPEK and OGEP.

\begin{tabular}{|l|c|c|c|c|}
\hline \multicolumn{5}{|c|}{ Time (h) } \\
\hline Cell Type & $\mathbf{4}$ & $\mathbf{2 4}$ & $\mathbf{4 8}$ & $\mathbf{7 2}$ \\
\hline OPEK & $0.03(0.02$ to 0.04$)$ & $0.05(0.04$ to 0.06$)$ & $0.08(0.07$ to 0.09$)$ & $0.11(0.10$ to 0.12$)$ \\
\hline OGEP & $0.04(0.04$ to 0.05$)$ & $0.07(0.07$ to 0.10$)$ & $0.11(0.11$ to 0.14$)$ & $0.13(0.12$ to 0.15$)$ \\
\hline
\end{tabular}



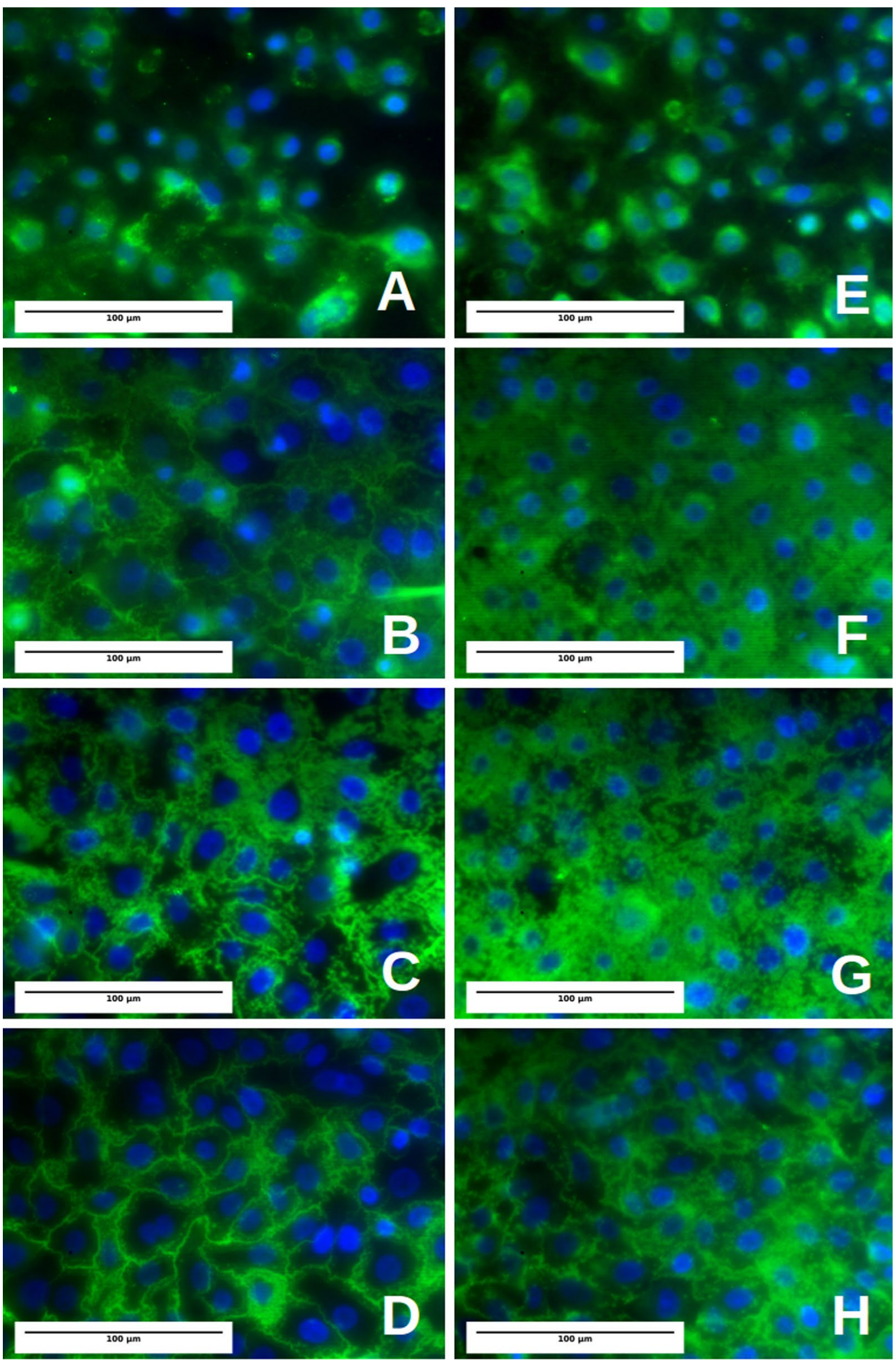

Fig. 8. Laminin-332 expression Assay: Fluorescent microscopy images of HPEK at $4 \mathrm{~h}(\mathbf{A}), 24 \mathrm{~h}(\mathbf{B}), 48 \mathrm{~h}(\mathbf{C})$ and $72 \mathrm{~h}(\mathbf{D})$ and HGEP at $4 \mathrm{~h}(\mathbf{E}), 24 \mathrm{~h} \mathrm{(F),} 48 \mathrm{~h}(\mathbf{G})$ and $72 \mathrm{~h}(\mathbf{H})$. 

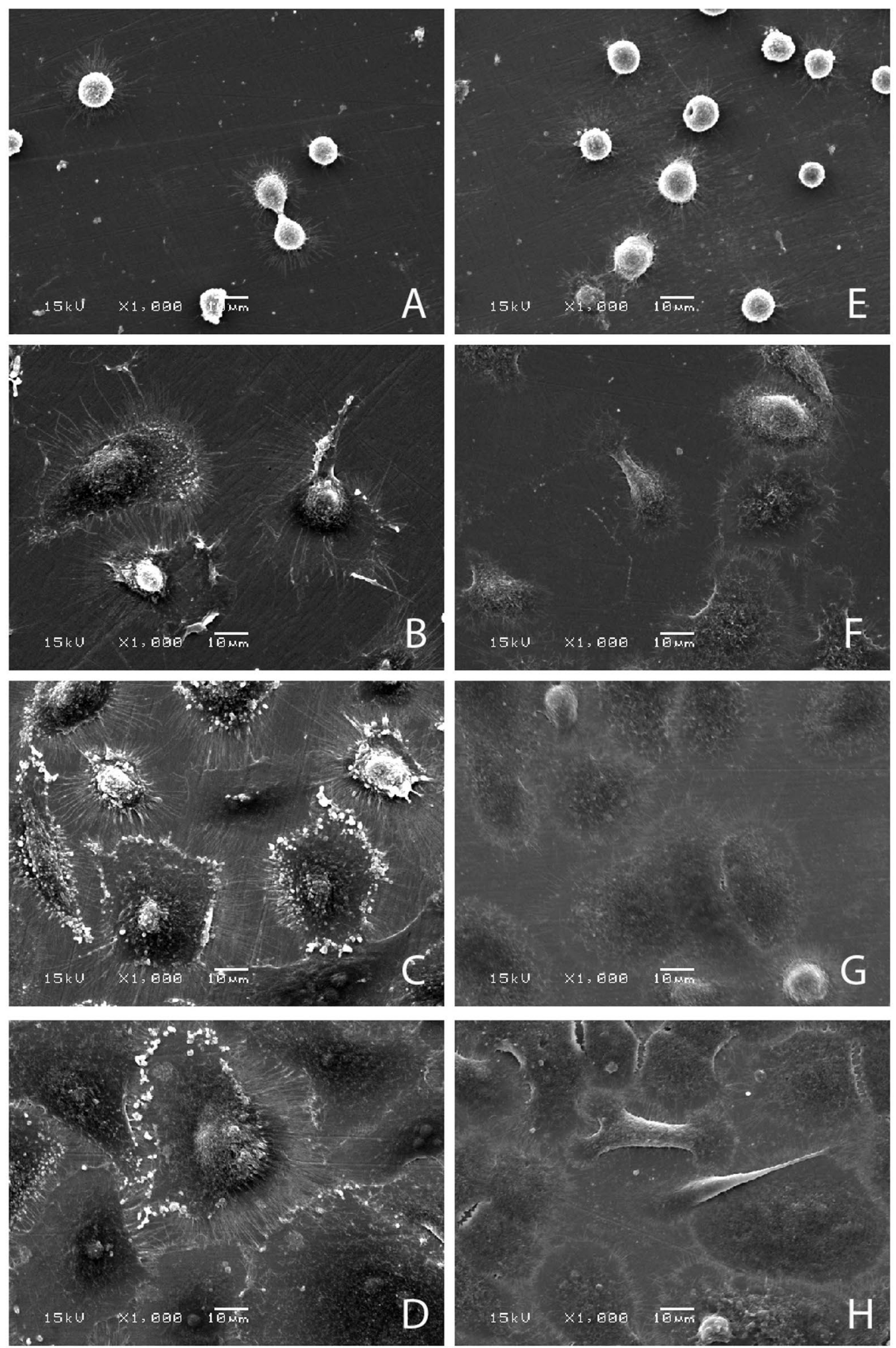

Fig. 9. Experiment two: Scanning electron microscopy images of OPEK at $4 \mathrm{~h} \mathrm{(A)}, 24 \mathrm{~h} \mathrm{(B)}, 48 \mathrm{~h}(\mathbf{C})$ and $72 \mathrm{~h}$ (D) and OGEP at $4 \mathrm{~h} \mathrm{(E),} 24 \mathrm{~h}(\mathbf{F}), 48 \mathrm{~h}(\mathbf{G})$ and $72 \mathrm{~h}(\mathbf{H})$.

Table 3. Median and $95 \%$ Confidence intervals for Experiment Two BP180 scores over time for OPEK and OGEP.

\begin{tabular}{|l|c|c|c|c|}
\hline \multicolumn{5}{|c|}{ Time (h) } \\
\hline \multirow{2}{*}{ Cell Type } & $\mathbf{4}$ & $\mathbf{2 4}$ & $\mathbf{4 8}$ & $\mathbf{7 2}$ \\
\hline OPEK & $1.0(0.6$ to 1.0$)$ & $1.0(0.9$ to 1.4$)$ & $2.0(2.2$ to 2.7$)$ & $4.0(4.0$ to 4.4$)$ \\
\hline OGEP & $3.0(2.6$ to 3.2$)$ & $3.0(2.8$ to 3.4$)$ & $4.0(4.0$ to 4.5$)$ & $4.0(4.3$ to 4.6$)$ \\
\hline
\end{tabular}


4 and $24 \mathrm{~h}(p<0.001)$, and between 24 and $48 \mathrm{~h}$ $(p<0.001)$; however, no significant increase was observed thereafter $(p=0.226)$.

\section{Hemidesmosome quantification and analysis}

The data are presented in Table 3 and Fig. 7. The BP180 score was significantly greater in OGEP compared with OPEK at $4(p<0.001), 24(p<0.001), 48(p<0.001)$ and $72 \mathrm{~h}(p=0.023)$. Unlike the human cells, morphological differences were not observed between the two primary ovine cell types. The BP180 score was 3 times greater for OGEP compared with OPEK at both 4 and $24 \mathrm{~h}$, and 2 times greater at $48 \mathrm{~h}$.

Over time, data analyses for each cell type showed that BP180 score significantly increased between all time points in OPEK ( $p$ values $=0.033$ (between 4 and $24 \mathrm{~h}),<0.001$ (24 and $48 \mathrm{~h}$ ) and $<0.001$ (48 and $72 \mathrm{~h}$ ); however, similar significant increases were only observed in OGEP between 24 and $48 \mathrm{~h}(p<0.001)$, and 48 and $72 \mathrm{~h}(p<0.001)$. No significant increase was observed in OGEP between 4 and $24 \mathrm{~h}(p=0.344)$. These findings support those for the unmatched human cell data.

\section{Laminin-332 expression assay}

The results are presented in Fig. 8. At $4 \mathrm{~h}$, the abundance and localisation of laminin-322 expression appear to be similar between HPEK and HGEP, however at 24 and $48 \mathrm{~h}$, expression in HGEP appears to be more abundant and distributed evenly over the surface of the substrates (both beneath and between cells). In contrast, expression in HPEK is located primarily between cells - with only limited evidence of localised expression at the cellsubstrate interface at 24 and 48 h. At 72 h, laminin-332 remains more abundant in HGEP cultures, with expression observed both between cells and at the cell-substrate, whist in HPEK, the expression is almost entirely observed at the cell-cell boundaries.

\section{Scanning electron microscopy}

The data are presented in Fig. 9. At $4 \mathrm{~h}$, the OGEP adopted a flatter morphology with more numerous cytoplasmic processes compared with the OPEK, typical of cells forming earlier cell-substrate attachments. By $48 \mathrm{~h}$, the substrates were supporting monolayers of both cell types; however, OGEP were seen to be adopting a flatter morphology with more continuous monolayers compared with OPEK. This persisted up to $72 \mathrm{~h}$.

\section{Discussion}

This is the first study to directly compare oral gingival epithelial cell and epidermal keratinocyte adhesion to titanium alloy in vitro. We have demonstrated that for pooled human, and matched ovine cells, oral gingival derived cells up-regulate both focal adhesion and hemidesmosome expression at earlier time points compared with epidermal keratinocytes. With pooled human cells, this up-regulation was significant for both focal adhesion and hemidesmosome expression at $4 \mathrm{~h}$, and for matched ovine cells, at all time-points.

Raisanen et al. showed that focal adhesions develop earlier than hemidesmosomes in epidermal keratinocytes, and this is consistent with the results of our current study (Raisanen et al., 2000). Pendegrass et al. demonstrated that hemidesmosome and focal adhesion expression significantly increase over time for immortalised human keratinocytes cultured on titanium alloy (Pendegrass et al., 2008). Our current findings substantiate this with primary pooled human and primary matched ovine epidermal keratinocytes. However, it is of note that there is no significant increase in hemidesmosome expression for gingival cells between 4 and $24 \mathrm{~h}$. For pooled human and matched ovine gingival cells, the expression of BP180 was found to be 1.5 and 3 times greater than epidermal keratinocytes at $4 \mathrm{~h}$. This demonstrates that the up-regulation occurred in the first $4 \mathrm{~h}$ of cell contact with the substrates and we postulate that this early attachment is key to the success of the transcutaneous interface observed in dental implants. Since hemidesmosomes are considered to 'enforce stable attachment of basal cells to the basement membrane in stratified epithelia' (Goldfinger et al., 1999), we also propose that gingival cells attach to titanium alloy more strongly than epidermal keratinocytes and, combined with earlier adhesion, this may play a role in the success of dental implant interfaces. We have observed a greater amount and more ubiquitous distribution of laminin-332 expressed by HGEP at 24, 48 and $72 \mathrm{~h}$, compared with HPEK. Since the $\alpha 6 \beta 4$ integrin binds with laminin-332 (Aumailley et al., 2005), this is consistent with our findings for vinculin and hemidesmosome expression and supports our hypothesis. Despite this, at $4 \mathrm{~h}$ we did not observe a difference in either abundance or distribution of laminin-332 between cell types. It is possible that the increased hemidesmosomes expressed in HGEP cells at this time point, are not yet associated with the ECM laminin-332. Temporal transcription and translation pathways of the two lag behind one another, such that hemidesmosome expression precedes that of laminin-332. This would require further research beyond the remit of this paper. However, we also accept that additional components of the ECM, including other laminin isoforms, type IV collagen, nidogen and heparin sulphate may also play important roles in the complex process of cell attachment. There would be merit in investigating these in addition. We acknowledge that our use of titanium alloy differs from that of commercially pure titanium, which is most frequently utilised in the dental implant field, and the results seen with this surface may be different from that seen with commercially pure titanium. However, the differences were not specific to the titanium surface but rather to the type of cell. For ITAP, titanium alloy provides improved biocompatibility, higher tensile strength and improved fatigue resistance compared with commercially pure titanium, making it the material of choice for trans-femoral implants, as the implant has to sustain large loads associated with walking.

The results of this study suggest that up-regulation of epidermal keratinocyte attachment around ITAP may 
enhance the skin seal. This premise is based on the fact that the problems of implant infection around dental implants are less than with transcutaneous implants and that one reason may be the relatively poor adhesion characteristics of cutaneous epidermal cells compared with gingival cells. However, we acknowledge that this may not be the only factor involved in the formation of an effective skin seal and other parameters, e.g. cell proliferation and migration, may also be important in the formation and maintenance of the interface in vivo. One of the key features of the soft tissues around the tooth and dental implant abutments is the tightly adherent nature of the soft tissues, where there is limited movement. This is in contrast to the skin, which is highly mobile and one of the key features of a successful transcutaneous implant is associated with limiting this movement. However, the adhesion of the epithelium to the implant surface is important in maintaining a long lasting functional seal.

Based on this paper, augmentation strategies to promote earlier epidermal keratinocyte attachment may prove beneficial in developing a seal at the transcutaneous interface. The attachment of the marginal gingiva to a tooth surface is mediated by the thin non-keratinised JE, which attaches to the tooth surface through hemidesmosomes and the IBL (Bosshardt et al., 2005; Ikeda et al., 2000; Masaoka et al., 2009; Oksonen et al., 2001; Shimono et al., 2003; Shiraiwa et al., 2002). The JE that develops around dental implants contains laminin-332 and is expressed by cells of the oral mucosa (Masaoka et al., 2009). The oral mucosa is the site from which the gingival cells for this study were derived. The success of the transcutaneous interface around teeth and dental implants can be attributed to JE, and specifically to the $\alpha 6 \beta 4$ integrin component of hemidesmosomes (Masaoka et al., 2009; Oksonen et al., 2001; Shimono et al., 2003) and the laminin-332 component of the IBL (Ikeda et al., 2000; Fukano et al., 2006). The IBL has been shown to contain a 12-fold higher laminin-332 content compared with the rest of the JE (Kinumatsu et al., 2009). We hypothesised that the attachment characteristics of the cells from the two sources would have different attachment capabilities and that laminin-332 may be in part responsible for this. This we have shown the former to be correct, and there to be a distinct difference in the abundance and special distribution of laminin-332 in the cells extracellular matrices. Laminin-332 (L5); is known to bind to the $\alpha 6 \beta 4$ integrin of hemidesmosomes mediating cell attachment to the basal lamina of both oral and extra-oral epithelial cells and this has been shown to gradually increase over time in oral gingival epithelial cell cultures on titanium alloy (Shiraiwa et al., 2002) where it regulates epidermal cell migration and attachment in wound healing (Goldfinger et al., 1999). Based on our findings and those of others, implicating laminin-332 in enhancing human epidermal keratinocyte attachment to titanium alloy (Ikeda et al., 2000), it may have a role to play in improving attachment at the skinimplant interface in clinical application. Covalently attaching laminin-332 through silanisation has been shown to up-regulate vinculin cell attachment markers in keratinocytes in vitro (Gordon et al., 2010). The consequences of attachment of laminin-332 molecules to the implant surface has been shown to be beneficial for the attachment of keratinocytes in vitro but the success of this for improving the skin-implant interface (in vivo) remains to be demonstrated.

\section{Conclusion}

This study has provided evidence that gingival derived cells up-regulate focal adhesion and hemidesmosome expression at earlier time points compared with epidermal keratinocytes when cultured on titanium alloy substrates and that laminin-332 expression may be in part responsible for these findings. Hemidesmosome expression in oral gingival cells was found to be $3 \times$ greater compared with that of epidermal keratinocytes at $4 \mathrm{~h}$. This early attachment may be responsible for formation of a successful gingival-implant interface around dental implants. If strategies could be developed to promote earlier and stronger keratinocyte adhesion to the biomaterials used for extra-oral transcutaneous devices, the associated issues of downgrowth and infection may be prevented, enabling ITAP to be used clinically with an effective infection-free skin seal.

\section{References}

Adell R, Hansson BO, Branemark PI, Breine U (1970). Intraosseous anchorage of dental prostheses. II. Review of clinical approaches. Scand J Plastic Recon Surg 4: 19-34.

Adell R, Lekholm U, Rockler B (1986). Marginal tissue reactions at osseointegrated titanium fixtures (I). A 3-year longitudinal prospective study. Int J Oral Maxfac Surg 15: 39-52.

Aumailley M, Bruckner-Tuderman L, Carter WG, Deutzmann R, Edgar D, Ekblom P, Engel J, Engvall E, Hohenester E, Jones JC, Kleinman HK, Marinkovich MP, Martin GR, Mayer U, Meneguzzi G, Miner JH, Miyazaki K, Patarroyo M, Paulsson M, Quaranta V, Sanes JR, Sasaki T, Sekiguchi K, Sorokin LM, Talts JF, Tryggvason K, Uitto J, Virtanen I, von der Mark K, Wewer UM, Yamada Y, Yurchenco PD (2005). A simplified laminin nomenclature. Matrix Biol 24: 326-332.

Bosshardt DD, Lang NP (2005). The junctional epithelium: from health to disease. J Dent Res 84: 9-20.

Branemark PI, Albrektsson T (1982). Titanium implants permanently penetrating human skin. Scand J Plast Reconstr Surg 16: 17-21.

Dudek NL, Marks MB, Marshall SC, Chardon JP (2005). Dermatologic conditions associated with use of a lower - extremity prosthesis. Arch Phys Med and Rehabil 86: 659-663.

Fukano Y, Knowles NG, Usui ML, Underwood RA, Hauch KD, Marshall AJ, Ratner BD, Giachelli C, Carter WG, Fleckman P, Olerud JE (2006). Characterization of an in vitro model for evaluating the interface between skin and percutaneous biomaterials. Wound Rep Regen 14: 484-491. 
Goldfinger LE, Hopkinson SB, DeHart GW, Collawn S, Couchman JR, Jones JC (1999). The alpha-3 laminin subunit, alpha6beta4 and alpha3beta1 integrin coordinately regulate wound healing in cultured epithelial cells and in the skin. J Cell Sci 112: 2615-2629.

Gordon DJ, Bhagawati DD, Pendegrass CJ, Middleton CA, Blunn GW. J Biomed Mater Res A 94: 586-593.

Hansson HA, Albrektsson T, Branemark PI (1983). Structural aspects of the interface between tissue and titanium implants. J Prosthet Dent 50: 108-113.

Ikeda H, Yamaza T, Yoshinari M, Ohsaki Y, Ayukawa Y, Kido MA, Inoue T, Shimono M, Koyano K, Tanaka T (2000). Ultrastructural and immunoelectron microscopic studies of the peri-implant epithelium-implant interface of rat maxilla. J Peridontol 71: 961-973.

Kinumatsu T, Hashimoto S, Muramatsu T, Sasaki H, Jung HS, Yamada S, Shimono M (2009). Involvement of laminin an dintegrins in adhesion and migration of junctional epithelium cells. J Peridontal Res 44: 13-20.

Lyon CC, Kullkarni J, Zimerson E, Van Ross E, Beck MH (2000). Skin disorders in amputees. Am Acad Dermatol 42: 501-507.

Marks JL, Michael JW (2001). Science, medicine and the future: Artifical limbs. Br Med J 323: 732-735.

Masaoka T, Hashimoto S, Kinumatsu T, Muramatsu T, Jung HS, Yamade S, Shimono M (2009). Immunolocalisation of laminin and integrin in regenerating junctional epithelium of mice after gingivectomy. J Periodontal Res 44: 489-495.

Middleton CA, Pendegrass CJ, Gordon D, Jacob J, Blunn GW (2007). Fibronectin silanized titanium alloy: A bioinductive and durable coating to enhance fibroblast attachment in vitro. J Biomed Mater Res A 83: 10321038 .

Odman J, Lekholm U, Jemt T, Branemark PI, Thilander B (1988). Osseointegrated titanium implants - a new approach in orthodontic treatment. Eur J Orthod 10: $98-105$.

Oksonen J, Sorokin LM, Virtanen M, Hormia M (2001). The junctional epithelium around murine teeth differs from gingival epithelium in its basement membrane composition. J Dent Res 80: 2093-2097.

Pendegrass CJ, Goodship AE, Blunn GW (2006a). Development of a soft tissue seal around bone anchored transcutaneous amputation prostheses. Biomaterials 27: 4183-4191.

Pendegrass CJ, Goodship AE, Price JS, Blunn GW (2006b). Nature's answer to breaching the skin barrier: An innovative development for amputees. J Anat 209: 59-67.

Pendegrass CJ, Gordon D, Middleton CA, Man Sun S Ng, Blunn GW (2008). Sealing the skin barrier around transcutaneous implants: In vitro study of keratinocyte proliferation and adhesion in response to surface modifications of titanium alloy. J Bone Joint Surg Br 90: 114-121.

Pendegrass CJ, Middleton CA, Gordon D, Jacob J, Blunn GW (2010). Measuring the strength of dermal fibroblast attachment to functionalised titanium alloys in vitro. J Biomed Mater Res A 92: 1028-1037.

Raisanen L, Kononen M, Juhanoja J, Varpavaara P, Hautaniemi J, Kivilahti J, Hormia M (2000). Expression of cell adhesion complexes in epithelial cells seeded on biomaterial surfaces. J Biomed Mater Res 49: 79-87.

Shimono M, Ishikawa T, Enokiya Y, Muramatsu T, Matsuzaka KI, Inoue T, Abiko Y, Yamaza T, Kido MA, Tanaka T, Hashimoto S (2003). Biological characteristics of the junctional epithelium. J Electron Microsc (Tokyo) 52: 627-639.

Shiraiwa M, Goto T, Yoshinari M, Koyano K, Tanaka $\mathrm{T}$ (2002). A study of the initial attachment and subsequent behaviour of rat oral epithelial cells cultured on titanium. J Periodontol 73: 852-860.

Tillander J, Hagberg K, Hagberg L, Branemark R (2010). Osseointegrated titanium implants for limb prostheses attachments: infectious complications. Clin Orthop Relat Res 468: 2781-2788.

Walko G, Castañón MJ, Wiche G (2014). Molecular architecture and function of the hemidesmosome. Cell Tissue Res [Epub ahead of print] PMID: 25487405.

Editor's Note: All questions/comments by the reviewers were answered by text changes. Therefore, there is no Discussion with Reviewers section. 